and in Nos. 7, 17, 20 and 24 on the fourth or fifth day, falling in each case on the exhibition of a cathartic. In none of the other cases did the temperature rise above $100^{\circ}$ at any time during the puerperium. So that a practical freedom from sepsis may be claimed for all except Nos. 13 and 22.

The conclusion I would draw from this study of cases is, that it is possible, by careful attention to a few simple details, to banish the severer forms of puerperal sepsis even from the homes of the very poor.

AUTH : RS QUOTED.

Reynolds. Puerperal sepsis in Massachusetts. Boston Medical and Surgical Journal, vol. exxxi, p. 153.

Reynolds. Practical midwifery, pp. 87-8.

Holmes. Medical essays: The contagiousness of puerperal fever.

Price. Obstetric asepsis. Boston Medical and Surgical Journal, vol. cxxx, p. 32.

Call. Report of the New England Hospital. Boston Medical and Surgical Journal, vol. cxxx, p. 40.

\section{TWO CASES OF CYST OF THE FINGER.'}

BY F. M. BRIGGS, M.D.,

Surgeon to the Boston Dispensary.

Cyst of the finger is a great rarity, and, of the two cases which I have to report, one is apparently unique as I can find no record of any similar case; of the second case very few have been reported.

I. ENCYSTED HEMATOMA OF THE FINGER.

A female, adult, came to the Boston Dispensary the latter part of February, 1895. She had a curiouslooking enlargement on the palmar surface of one of the fingers. It was firm, non-fluctuating and slightly painful on pressure. The patient stated that two years previously she ran a sharp piece of tin into the finger at this point, that she pulled it out, and that so far as she knew, it all came out. The finger immediately swelled up, and this swelling had never gone down.

I made a short cut through the skin, exposed a cyst wall, and by pressure a small bean-shaped cyst came out. It was white and glistening, and upon cutting it in halves, showed a thick cyst wall surrounding an almost black, soft, solid mass, suggestive of some form of altered blood.

Dr. W. F. Whitney reports as follows regarding it : "The tumor was of a cystic character, about the size and shape of a small bean. The interior was filled with a very dark, granular material, and the wall was of cartilaginous density. The contents were made up of granules of coloring matter (altered blood pigment) and irregular scaly fragments. The wall was an extremely dense, fibrous tissue with an occasional nucleus. The diagnosis is a small encysted hematoma."

\section{EPIDERMOID CYST OF THE FINGER.}

A male, adult, age forty-two, presented himself in the early part of March, 1895, with a large swelling of the terminal phalanx of the second finger on its palmar surface. It was tense, fluctuating, slightly painful on pressure and of irregular shape. The history was very unsatisfactory and of no diagnostic value. I injected cocaine, and upon withdrawing the needle a few drops of milky fluid followed it. 1 Read before the Surgical Section of the Suffolk District Medical
Society, April 3, 1895 .
I made a V-shaped flap, under which I found a cyst wall, which was not adherent to the skin but was firmly adherent to the tendon. It came away with great difficulty, and in removing it the contents were lost. They were milky, and contained some greasylooking particles, but nothing cheesy. The cyst measured two inches in circumference, and five-eighths of an inch in diameter.

At the next visit the man gave a history of the finger. He said that sixteen years previously he had a felon with complete healing and nothing noticeable afterwards. That six years ago the finger was crushed, and after it healed it was somewhat enlarged. That his attention was called to its increasing size about three weeks previously, when it was very painful and the skin over it was reddened.

Dr. Whitney's report is: "The growth was a cyst the size of a large cherry $(17 \mathrm{~mm}$.), the outer surface quite smooth, and the inner roughened and covered with adherent scaly masses. The wall was of firm consistency. Microscopic examination showed the wall to be made up of an outer layer of more or less flattened epithelial cells, which were gradually transformed into flat lamellated scales, and from their deeply staining with picric acid gave evidence of a transformation into a horuy substance. In the part examined nothing but this epidermoid growth was found. The diagnosis was an epidermoid cyst."

Epidermoid cyst of the finger has been variously called dermoid, dermal, epidermal, implantation and traumatic epithelial cyst. I find 18 reported cases. Garré of Tübingen, who reports two of them, states that 29 such cases have beeu reported previous to 1894. The first case of the kind of which I find record was reported by Rizet in $1866 .^{2}$

Of the 18 cases which I have personally found reported, 11 are in France, four in England, two in Germany and one in Switzerland. I find none reported in this country.

The condition is evidently a very rare one. It is certainly a very interesting one. The gross appearance is that of an ordinary wen. But there are no sebaceous glands in the palm of the finger; the cyst wall of a wen is composed of fibrous connective tissue and has nothing resembling the structure of the skin.

One theory is that these cysts are true dermoid and that in the cases where they occur there was an em. bryonic inclusion at this point. But they have never yet been found in children and seldom at puberty. They usually occur in adults. No case has been reported containing hair, teeth, nails or other of the contents found in dermoid cysts. Plastic heterotopia, or formation of tissue in unusual places, has also been advocated as the explanation. It seems to me that this is not an explanation.

It is a noteworthy fact that in all cases the cyst follows an injury of the affected finger. It is also to be noted that the wall of this cyst is skin-like in structure. These two facts have led to the belief, in which the writer concurs, that these cysts are due to preceding injury in which a fragment of skin is forced in and transplanted subcutaneously. This theory is made highly probable by the experimental work of Kaufman, ${ }^{8}$ who implanted fragments of epithelium under the skin of guinea-pigs and found cysts forming in two weeks.

2 Included in Lalitte's series. See references.

s Virchow's Archiv, 97 Bd. 
The one argument against this theory is that if this is the explanation, if they are the result of an injury, epidermoid cysts would be much more common.

I have been very much interested in looking up the subject to see if any satisfactory answer has been given to this question, for it was what first occurred to me when I found the traumatic theory advanced. But I have found none, and at the same time feel convinced that we have here the true explanation of the condition.

In the absence of proof, one theory is, of course, as good as another. I advance a theory which may account for the very great discrepancy between the vast number of finger injuries and the fact that in the past thirty years only about thirty of these injuries have been followed by epidermoid cysts :

A fragment of skin may be very frequently carried in at the time of the injury, but it is almost invariably either killed by the injury or is disposed of in the healing process. But, once in a great many thousand times, this fragment retains its vitality, becomes engrafted on the subcutaneous tissues and after a dormant period of, usually, from four months to two years the cyst develops.

The point is made by some writers that these cysts are invariably attached to the under surface of the skin and are always free from the deep tissues. This face.

is by no means a fact. The case which 1 report was not adherent to the skin, but was firmly adherent to the tendon. One case reported by E. C. Stabb in 1890 was adherent to both the skin and the tendon, and a second case by the same writer was not attached to either the skin or the tendon.

Epidermoid cyst of the finger, therefore, is a cyst which follows, and is probably due to, an injury of the affected finger. It may develop in a few months, but, as a rule, cannot be demonstrated under one year, and often does not enlarge to any extent for several years after the injury.

It is probably the result of an engrafting on the subcutaneous tissues of a fragment of skin, which is carried in at the time of the injury, and which retains sufficient vitality to withstand both the immediate effect of the injury and the later efforts of nature to dispose of it.

The resultant cyst may be adherent to the skin and the tendon, to either alone, or to neither.

A diagnosis can only be made by the microscope, where a section of the cyst wall must show a resemblance to true-skin structure. This is usually epidermal in character, but is, exceptionally dermal, and shows not only an epidermoid structure, but also the structure of the cutis vera. Sebaceous glands and hair follicles are not found.

In some cases the skin structure is seen in au inverted order; that is to say, as in the case here reported, the horny layer is on the inside. In others no such inversion is present. The contents are milky, cheesy, or both.

Regarding its name, epidermoid is the best general definition of the condition, for although some of the cases have shown more than an epidermal layer, most of them contain only the structure of the epidermis.

If it is granted that they are due to an injury, the terw traumatic is superfluous; and if it should be proved that they are not due to injury, it is erroneous.

Regarding the theory which $I$ have already referred to, that they are true dermoids and due to embryonic inclusion, I will further say that one such case as the one I report is strong evidence against such a theory, for the wall of congenital (inclusion) cyst does not show an inversion of the dermal structure.

The only treatment is removal, and in operating, the sac should be carefully dissected out, for recurrences have been reported.

Regarding other forms of cyst of the finger, I find one case reported ${ }^{4}$ where a cyst wall formed about a needle broken in the tinger three years previously.

I do not know whether molluscum ever occurs here, but if it does it can be easily distinguished. It is in the superficial layers of the skin from which it projects. It is never subcutaneous.

Sudoriparious cyst is referred to by a few writers, but as they simply speak of it as a possible occurrence and give no data, it can be disregarded. In any given case the microscope would show a different structure of the skin wall.

Similarly of synovial cyst. If found in the finger, the wall is not epidermoid in character, and, moreover, the contents are those of ganglion and bursa in other locations.

Pearl tumor (cholesteatoma) is a small, round tumor, with pearly exterior, which is said to be due to superimposed layers of cholesterin on its external sur-

Councilman 5 says: "It is essentially a tumor of the cerebrum but may occur elsewhere. The tumor is composed of cells resembling the horny layer of the epidermis. It is often surrounded by a well-defined capsule. When cut into, it is whitish yellow, and of the consistency of wax. Some authors regard them as dermoid cysts, but they never contain dermic structures, nor has a true epithelial structure been seen in the cyst which sometimes surrounds them."

From this description it will be seen, that if found in the finger, the microscope would distinguish them from the class under consideration.

In conclusion, it can be stated that cyst of the finger is an extremely rare condition; that the most common are the epidermoid cysts, but that isolated cases of other forms are reported, such as that of Kummer (the needle in a cyst) and the other one which I report of a blood cyst; that they are of interest on account of their infrequency and of importance on account of their location, for they hamper the free use of the finger. Free use of the finger is indispensable to the hand, and the value of the hand to the individual needs no comment.

\section{REFERENCES.}

Guermonprez, Fr. et J. Toisson. Journal de Sc. Méd. de Lille, 1885 , vii, p. 405 .

Barker, A. E. British Medical Journal, 1885, p. 871.

Lalitte, C. J. Diss. de la Faculté de Méd., Nancy, tome xx, 1885.

Guermouprez, Fr. Kystes des doigts, Paris, 1886.

Reverdin, J. et Mayor, A. Rev. Med. de la Suisse Rom., Geneva, 1887 , vii, p. 121 .

Van Becelaere, Fr. Bull. Soc. Anat. Clin. de Lille, 1887, ii, p. 239.

Stabb, E. C. 'Trans. Path. Soc. of London, 1890, I, xlii, p. 311.

Garré, C. Dermatolog. Zeitschraft, Berlin, 1894, 1, p. 45.

Labougle, J. Archiv. de Méd. et Pharm., 1894.

Sutton, J. B. British Medical Journal, March 2, 1895.

Coalition of Free Coinage and Medicine. A Texas medical journal offers to send a free copy of "Coin's Financial School" to each new subscriber.

4 Kummer : Revue de Chirurgie, Paris, 1891, xi, pp. 670-675.

5 Reference Hand-Book of the Medical Sciences, vol. iv, p. 138. 